\title{
Carcinoid tumour arising in a Meckel's diverticulum
}

\author{
J.J. Payne-James, N.W. Law and R.M. Watkins \\ Professorial Surgical Unit, Westminster Hospital, Page Street, London SW1P 2AP, UK.
}

\begin{abstract}
Summary: A patient with a carcinoid tumour arising in a Meckel's diverticulum and presenting with acute small intestinal obstruction is described. Review of previously reported cases indicates that the initial clinical presentation of carcinoid tumours occurring in a Meckel's diverticulum is usually similar to that of appendiceal carcinoids. While most carcinoids in Meckel's diverticula present as incidental findings at post-mortem examination or laparotomy, their metastatic potential and subsequent behaviour resembles that of other small intestinal carcinoid tumours.
\end{abstract}

\section{Introduction}

Carcinoid tumours account for one-fifth of all small intestinal neoplasms (Brookes et al., 1968) and are found most commonly in the terminal ileum (Godwin, 1975). Their occurrence in a Meckel's diverticulum, the most common congenital abnormality of the gastrointestinal tract, is rare. Following the original description in 1907 by Oberndorfer only 50 cases have been reported. A further case is presented and the features of argentaffin-cell tumours located in a Meckel's diverticulum are compared with those arising in the normal small intestine and the vermiform appendix.

\section{Case report}

A 72 year old man presented with a 7 day history of intermittent central abdominal pain. Twenty four hours before admission to hospital his pain became increasingly severe, he suffered nausea and vomiting and developed absolute constipation. There had been no previous gastrointestinal symptoms. A left aboveknee amputation had been performed for chronic osteomyelitis 32 years previously.

Abdominal examination revealed gross distension with generalized tenderness and obstructive bowel sounds. On digital examination the rectum was empty and ballooned but no masses were palpable. Plain abdominal radiographs showed grossly dilated loops of small intestine with multiple fluid levels. No gas shadows were seen in the large intestine.

Following naso-gastric aspiration and intravenous fluid replacement, laparotomy was performed. At operation several loops of grossly distended small

Correspondence: R.M. Watkins, M.A., F.R.C.S.

Accepted: 24 May 1985 intestine were found proximal to a Meckel's diverticulum measuring $3.2 \times 1.7 \times 1.3 \mathrm{~cm}$ and situated $60 \mathrm{~cm}$ proximal to the ileo-caecal valve. The diverticulum was inverted causing a localized obstruction but intussusception had not occurred, the distal small intestine being collapsed. There were no enlarged mesenteric nodes, the liver appeared normal and no other intraperitoneal abnormality was found. The segment of ileum containing the diverticulum was excised and small intestinal continuity re-established by end-to-end anastomosis. Apart from a superficial wound infection the patient's recovery was uneventful.

A yellow tumour $0.4 \mathrm{~cm}$ in diameter was present in the wall of the resected diverticulum near its apex. On microscopic examination the tumour comprised uniform small cells containing eosinophilic cytoplasm and arranged in cords and clumps. Masson-Fontana and diazo stains confirmed the presence of a carcinoid tumour.

The patient's urinary 5-hydroxyindoleacetic acid excretion in the immediate postoperative period was normal.

\section{Discussion}

Meckel's diverticulum is an unusual site for both benign and malignant neoplasms (Soltero \& Bill, 1976; Williams, 1981). In a review of 600 cases of Meckel's diverticulum presenting with complications, less than $4 \%$ were found to contain a tumour (Yamaguchi et al., 1978). After sarcomas, carcinoid tumours are the second commonest malignant tumour arising in Meckel's diverticulum (Weinstein et al., 1963).

Like argentaffin-cell tumours of the appendix (Dawes et al., 1984), carcinoid tumours occurring in a Meckel's diverticulum are usually small, the majority 
measuring $1 \mathrm{~cm}$ or less in diameter (Weitzner, 1969). Unlike other small intestinal carcinoids their size is not always related to the degree of invasion or distant spread. Metastases, which have been reported in onefifth of cases, involve the regional lymph nodes and liver. Of those patients with liver metastases $50 \%$ later develop the carcinoid syndrome (Jones et al., 1972). Dissemination is seen in one- to two-thirds of patients with other small intestinal carcinoids (Moertel et al., 1961; Godwin, 1975) compared with less than 5\% of patients with carcinoid tumours arising in the vermiform appendix (Godwin, 1975).

The majority of carcinoid tumours arising in Meckel's diverticulum are incidental findings at either postmortem examination or laparotomy for other conditions (Jones et al., 1972). Similarly, appendiceal carcinoids are usually discovered following incidental appendicectomy or appendicectomy for acute appendicitis (Dawes et al., 1984). In contrast almost half of all jejuno-ileal carcinoids present with small intestinal obstruction (Dawes et al., 1984). The mean age at which carcinoid tumours in Meckel's diverticulum are found is 55 years (Jones et al., 1972) compared with 60 years for other small intestinal carcinoids and 29 years for those in the appendix (Dawes et al., 1984). The fact that appendiceal carcinoids are seen at a much earlier age is partly explained by their common presentation as an incidental pathological finding following appendicectomy.

Small intestinal carcinoids are frequently multiple, more than one tumour being found in up to $30 \%$ of patients (Moertel et al., 1961; Dawes et al., 1984). In contrast multiple carcinoid tumours arising in a Meckel's diverticulum have been reported on only two occasions (Oberndorfer, 1907; Traill, 1968). Similarly, less than $5 \%$ of patients with appendiceal carcinoids have additional tumours (Moertel et al., 1968).
Carcinoid tumours within a Meckel's diverticulum are seen four times more commonly in men than women (Weitzner, 1969; Jones et al., 1972). This sex distribution probably reflects the higher incidence of both Meckel's diverticulum (Yamaguchi et al., 1978) and small intestinal carcinoids (Godwin, 1975) in men.

Of all carcinoid tumours, those arising in the appendix have the most favourable prognosis, with 5 years survival rates greater than $95 \%$ (Godwin, 1975). This compares with rates of $30-50 \%$ for small intestinal carcinoids (Brookes et al., 1968; Welch \& Malt, 1977). Information on the limited number of patients with carcinoid tumours in a Meckel's diverticulum is insufficient to predict accurately the prognosis of this tumour, only three patients having been followed up for more than 5 years since diagnosis (Jones et al., 1972).

The incidence of complications associated with Meckel's diverticulum declines progressively with age and is extremely low in elderly patients (Michas et al., 1975; Soltero \& Bill, 1976; Mackey \& Dineen, 1983). Prophylactic excision of a Meckel's diverticulum found incidentally at laparotomy in patients over 40 years is therefore no longer advised (Editorial, 1983). However, careful palpation of any diverticulum is always necessary to exclude the presence of a neoplasm which is more likely to be found in older patients. While most Meckel's diverticula can bec removed by simple excision, if a tumour is suspected formal ileal resection with excision of a wedge of mesentery is recommended (Williams, 1981).

\section{Acknowledgements}

We are grateful to Professor Harold Ellis for permission to report this case and for assistance in preparing this paper.

\section{References}

BROOKES, V.S., WATERHOUSE, J.A.H. \& POWELL, D.J. (1968). Malignant lesions of the small intestine. A ten-year survey. British Journal of Surgery, 55, 405.

DAWES, L., SCHULTE, W.J. \& CONDON, R.E. (1984). Carcinoid tumours. Archives of Surgery, 119, 375.

EDITORIAL (1983). Meckel's diverticulum: Surgical guidelines at last? Lancet, ii, 438.

GODWIN, J.D. (1975). Carcinoid tumours. An analysis of 2837 cases. Cancer, 36, 560.

JONES, E.L., THOMPSON, H. \& ALEXANDER WILLIAMS, J. (1972). Argentaffin-cell tumour of Meckel's diverticulum. A report of two cases and review of the literature. British Journal of Surgery, 59, 213.

MACKEY, W.C. \& DINEEN, P. (1983). A fifty-year experience with Meckel's diverticulum. Surgery, Gynecology and Obstetrics, 156, 56.
MICHAS, C.A., COHEN, S.E. WOLFMAN, E.F. (1975). Meckel's diverticulum. Should it be excised incidentally at operation? American Journal of Surgery, 129, 682.

MOERTEL, C.G., SAUER, W.G., DOCKERTY, M.B. \& BAGGENSTOSS, A.H. (1961). Life history of the carcinoid tumour of the small intestine. Cancer, 14, 901.

MOERTEL, C.G., DOCKERTY, M.B. \& JUDD, E.S. (1968). Carcinoid tumours of the vermiform appendix. Cancer, 21, 270.

OBERNDORFER, S. (1907). Karzinoide tumoren des dunndarms. Frankfurter Zeitschrift fur Pathologie, 1, 426.

SOLTERO, M.J. \& BILL, A.H. (1976). The natural history of Meckel's diverticulum and its relation to incidental removal. American Journal of Surgery, 132, 168.

TRAILL, M.A. (1968). Dual carcinoids in a Meckel's diverticulum. Medical Journal of Australia, 2, 67. 
WEINSTEIN, E.C., DOCKERTY, M.B. \& WAUGH, J.M. (1963). Neoplasms of Meckel's diverticulum. International Abstracts of Surgery, 116, 103.

WEITZNER, S. (1969). Carcinoid of Meckel's diverticulum. Report of a case and review of the literature. Cancer, 23, 1436.

WELCH, J.P. \& MALT, R.A. (1977). Management of carcinoid tumours of the gastrointestinal tract. Surgery, Gynecology and Obstetrics, 145, 223.

WILLIAMS, R.S. (1981). Management of Meckel's diverticulum. British Journal of Surgery, 68, 477.

YAMAGUCHI, M., TAKEUCHI, S. \& AWAZU, S. (1978). Meckel's diverticulum. Investigation of 600 patients in Japanese literature. American Journal of Surgery, 136, 247. 